\title{
Strengthening the Humanistic Spirit in the Service of University Library
}

\author{
Yang Xing \\ Jilin Agricultural University, Changchun 130118, China \\ 37566208@qq.com
}

\begin{abstract}
The humanistic spirit is a universal human self-concern, whose purpose is to cultivate, purify and improve people's spiritual world and emotion, and promote the free and comprehensive development of human beings. In the relationship between man and nature, and man and society, the humanistic spirit adheres to people-oriented concept, cherishes the people's life, freedom, happiness and rights, respects personality independence, stresses on the life value, significance, ideals, and beliefs. Library humanistic spirit refers to the people-oriented concept reflected in the working practice of the library, which takes to meet people's requirements, realize human value, pursue human development, reflect humane care and create beauty and harmony as the purpose of the library activities. This paper investigates and analyzes humanistic level of three University libraries researched. At the same time, it also makes a study on how to strengthen the construction of humanistic spirit in library. The first one is to create a harmonious humanistic environment, including to improve the layout of the premises, perfect system environment, and create a harmonious interpersonal relationship; secondly, it is necessary to optimize library collection, enrich collection resources to meet the needs of readers. The third is to carry out a variety of services, and promote the construction of a harmonious campus.
\end{abstract}

Keywords: library; humanistic spirit; people-oriented; strengthening.

\section{Introduction}

\subsection{Research Background}

The core value of humanistic spirit is people-oriented concept, and it is a universal human self-care, whose purpose is to cultivate, purify, enhance people's spiritual world and emotional, and promote the free and overall development of human [1-3]. In the relationship between man and nature as well as man and society, the humanistic spirit adheres to humanism, cherishes the people's life, freedom, happiness and rights, respects personality independence, stresses on the life value, significance, ideals, and beliefs. Chinese humanistic spirit was originated from the people-oriented thought in Chinese traditional culture, which has a long historical tradition. Until the 1980s's cultural debate, it is related to the topic of "humanistic spirit". By the middle of 1990s, the humanistic spirit has become the most concerned research topic in the academic field. Mr. Jiang Yongfu firstly began to use the word "humanistic spirit" in the field of Library Theory in our country in 1991. In 1999, Mr. Wu Xi clearly put forward the concept of "library humanistic spirit" for the first time. Thereafter, library humanistic spirit has become a hot research spot in the field of library science.

\subsection{Research Situation at Home and Abroad}

Along with the rapid development of modern information technology and network technology, computer technology and network technology has brought earth shaking changes to the library. Foreign libraries make full use of modern information technology, at the same time, attach great importance to the construction of humanistic spirit in the library. Digital library second pilot program in the United States clearly takes "human-centered" as one of the three major research contents, and reflects the obvious characteristic of "around the users" in the vast majority of projects, such as the research on personalized information service system, information filtering technology, intelligent information service system and so on. In addition, PIE system developed by British Headline hybrid library project, My grid system jointly developed by Manchester University and other seven institutions, My Library system of Cornell and so on [4-6], are all doing comparatively perfect in the "people-oriented" humanized services. 
However, the establishment of the library humanistic spirit has not become a universal concept of social related aspects, and in general people tend to pay too much attention to the library "hardware" construction while ignore the construction of its humanistic spirit. Therefore, this paper attempts to make some exploration and research in this area.

\section{Humanistic Spirit of University Library}

\subsection{Formation and Development of the Library Humanistic Spirit}

(1) Origin and Development of the Library Humanistic Spirit in Foreign Countries

In the middle of $17^{\text {th }}$ century, the bourgeoisie began to set up a public library for serving for the common people. In the development of western libraries, the representative figures of humanism thought mainly include Ranganahan, Butler and so on. Ranganahan's library science theory contains a strong humanistic spirit. Butler's representative work An Introduction to Library Science, separately embarking from three different perspectives of the sociology, psychology, and history, theoretically expounds the books, library and library science, and any of the three aspects pays enough attention to the importance of humane factors. In the 1990s, the American Library Association pointed out that library has the obligation of providing information service for the general public, library should eliminate social barriers, library is the place that changes the social unfair phenomenon, library should also respect for the individual, open the door to everyone's and so on. With the development of the library enterprise, the service function of the western library has already penetrated into all aspects, making the library become an indispensable part of people's life.

(2)Origin and Development of the Library Humanistic Spirit in Domestic

The earliest library in our country is called the Library Collection Hall in the ancient times. Library Collection Hall is monopolized by the feudal rule, which is used by the ruler. Due to the development of society, the input of western library concept, the feudal Library Collection Hall gradually declined. By the beginning of $20^{\text {th }}$ century, the open modern library, which was open and that took public used books as the mark began to appear in China [7]. After 1980s, the scale of the public library has expanded rapidly, and the library has opened to the outside world.

In the literature of Library Science Theory, Mr. Jiang Yongfu began to use the word "humanistic spirit" in The Library Science Is also a Kind of Human Study published in 1991, which is the prototype of the library humanistic spirit. In 1999, Mr. Xiao Ximing put forward clearly the name of library humanistic spirit for the first time, and sublimated library humane tradition to humanistic spirit The Fusion of Science and Humanistic Spirit--the Library Goes towards $21^{\text {st }}$ Century published in 2001. In 2002, Ms. Zhu Xiaohua made relevant supplement in Modern Library and Traditional Humanistic Spirit: the library humanistic spirit is not only originated from the humanism, but the development, improvement, enrich and specification based on humanism. Thus, in the process of the modernization of the library, the development of the library humanistic spirit is the historical necessity.

\section{An Empirical Study on the Humane Level of University Library}

\subsection{Survey on the Current Situation of Humane Level of Library Service}

In recent years, library has made great progress in the premises, hardware equipment, information technology, network technology and multimedia technology, but lack understanding of humanistic importance and ignores the establishment, cultivation, and advocate of humanistic spirit of the library.

The questionnaire is divided into two parts: the first part is the basic information of University librarians, including the basic information of the investigated, like school, gender, job title, education degree and so on, to further analyze the difference of evaluation of librarians with different gender, professional title and academic qualifications on the library atmosphere and diversity of satisfaction situation. The second part is the main part of the questionnaire, which is library atmosphere and diversification of evaluation index evaluation subject, involving more than 60 multiple-choice questions. 


\subsection{Survey Data Analysis}

The questionnaire survey was approved by the guided by library directors and guided by the library's office secretary of the three universities investigated, and it is carried out under the natural state of librarians. Survey data analysis is as follows:

1) Satisfaction degree of librarians in different genders to the University library atmosphere and the diversification

Table 1 Gender distribution of the librarians in the University library

\begin{tabular}{|c|c|c|c|}
\hline & Male & Female & The total \\
\hline The number of the investigated & 46 & 99 & 145 \\
\hline Gender proportion & $31.7 \%$ & $68.3 \%$ & 1 \\
\hline
\end{tabular}

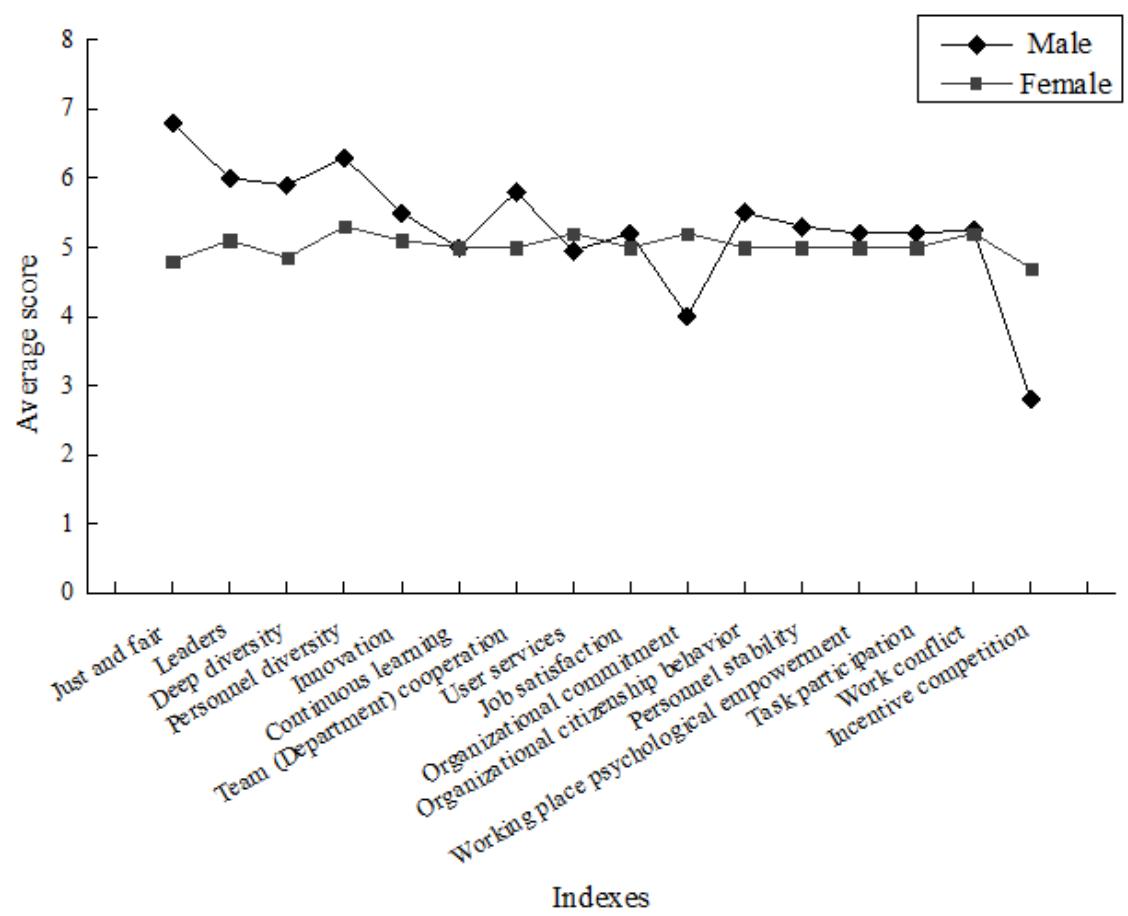

Figure 1 Satisfaction degree of librarians in different genders with the atmosphere and diversification of University library

2) Satisfaction degree of the librarians in different educational backgrounds to the atmosphere and the diversification of the University library

Table 2 Academic structure distribution of College librarian investigated

\begin{tabular}{|c|c|c|c|c|c|c|}
\hline & Specialty & Undergraduate & Master & Doctor & Others & $\begin{array}{c}\text { The } \\
\text { total }\end{array}$ \\
\hline $\begin{array}{c}\text { The number of } \\
\text { the investigated }\end{array}$ & 21 & 62 & 53 & 4 & 5 & 145 \\
\hline $\begin{array}{c}\text { Academic } \\
\text { proportion }\end{array}$ & $14.5 \%$ & $42.8 \%$ & $36.6 \%$ & $2.8 \%$ & $3.4 \%$ & 1 \\
\hline
\end{tabular}


3) Satisfaction degree of university librarian with different professional titles to the atmosphere and diversification

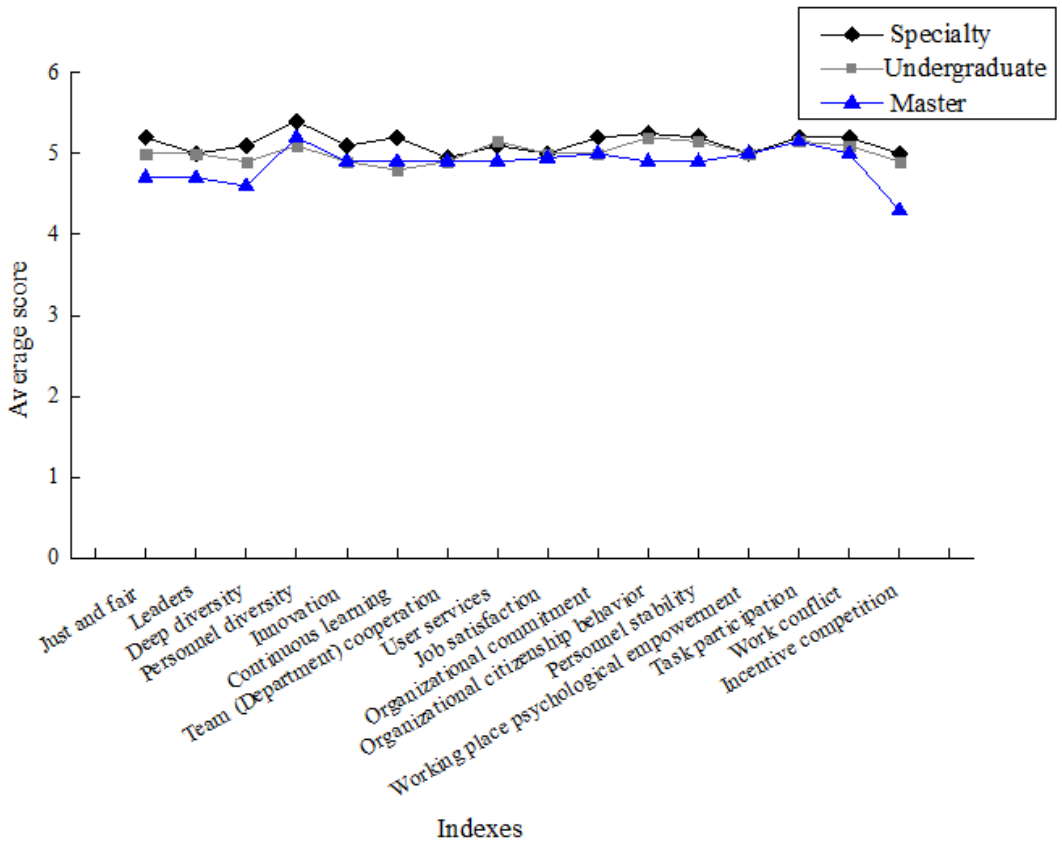

Figure 2 Satisfaction degree of librarians in different educational backgrounds to the atmosphere and diversity of University library

Table 3 Title structure distribution of librarians in University library

\begin{tabular}{|c|c|c|c|c|c|c|}
\hline & $\begin{array}{c}\text { Library } \\
\text { assistant }\end{array}$ & Librarian & $\begin{array}{c}\text { Associate } \\
\text { research librarian }\end{array}$ & $\begin{array}{c}\text { Research } \\
\text { librarian }\end{array}$ & Others & The total \\
\hline $\begin{array}{c}\text { The number of the } \\
\text { investigated }\end{array}$ & 54 & 65 & 15 & 1 & 10 & 145 \\
\hline Title proportion & $37.20 \%$ & $44.8 \%$ & $10.3 \%$ & $0.7 \%$ & $6.9 \%$ & 1 \\
\hline
\end{tabular}

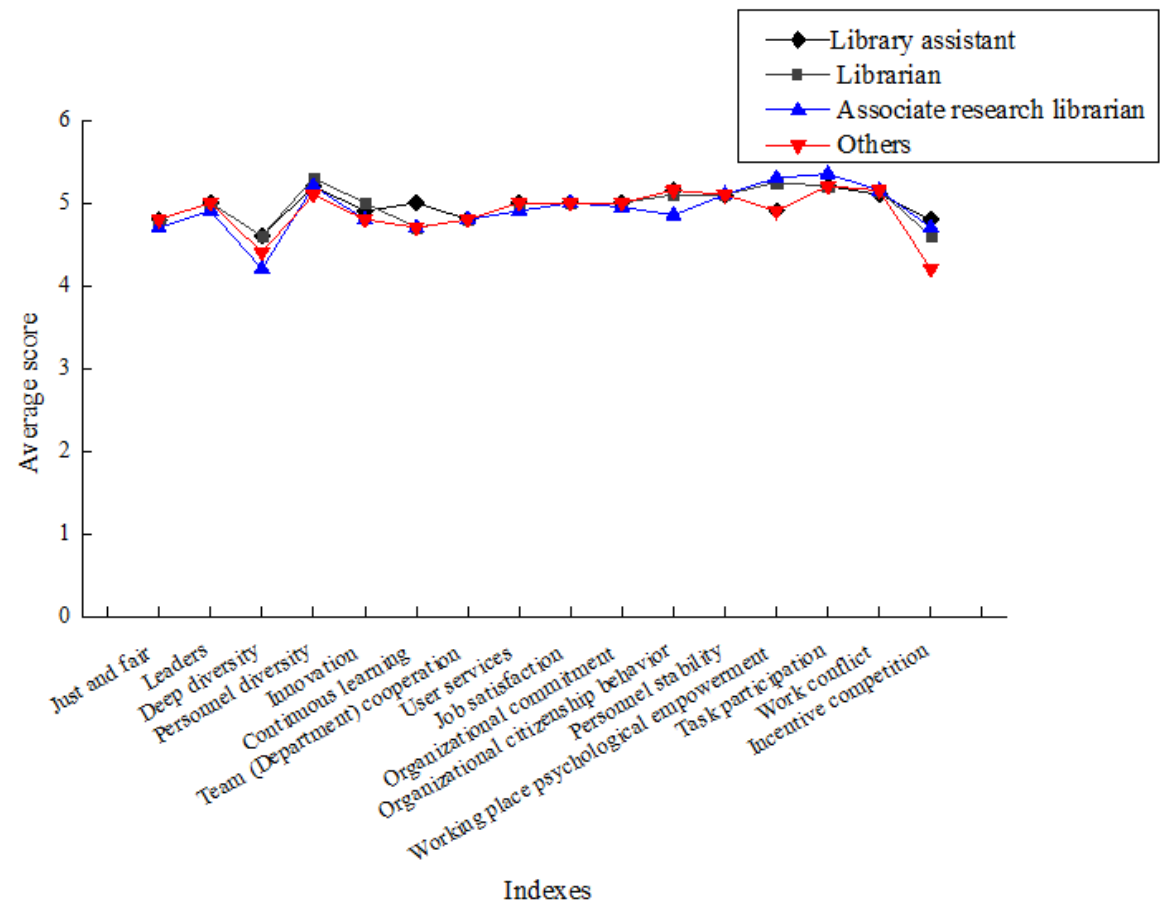

Figure 3 Satisfaction degree of librarians in different titles to the atmosphere and diversity of College library 
4) Comparison of organizational atmosphere and organizational attitudes of the library

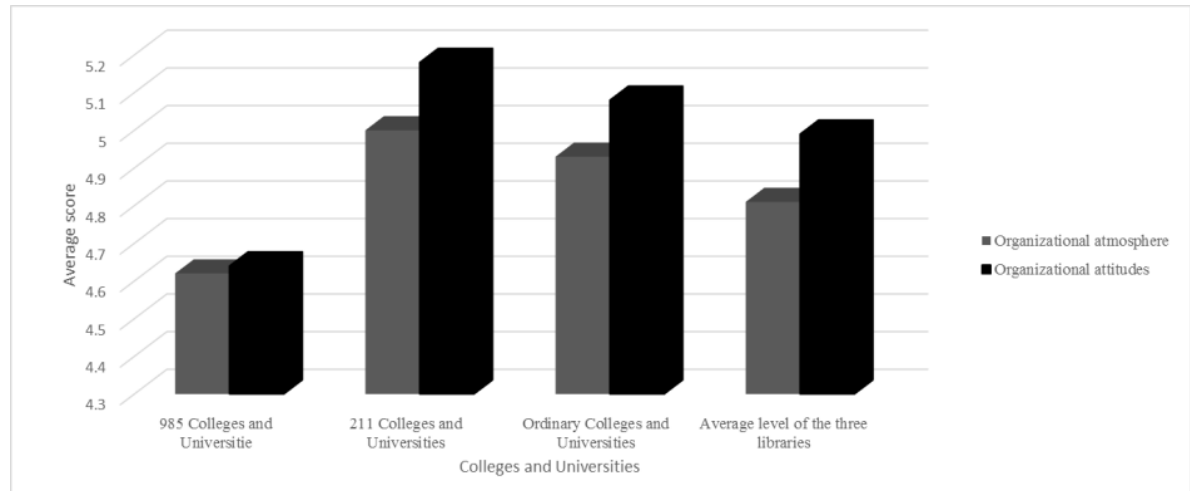

Figure 4 Comparison of organizational atmosphere and organizational attitudes of the library

\section{Strengthening the Construction of Humanistic Spirit in the Service of University Library}

\subsection{Take People as Orientation and Create a Harmonious Humanistic Environment}

University library building is a landmark of the University, and the site of University library should be selected in the center of the campus as far as possible, highlighting its landmark effect. The university library is the place where all the teachers and students do cultural activities. It is required to consider the relationship between library and the teaching area, living area, family area, student dormitory building and so on, facilitating the main body of teachers and students, and try to choose the location with a moderate position, convenient transportation, and quiet environment.

Architecture is a stereoscopic culture. The University library, in the architectural design, should pay attention to the use of different construction methods, building decoration and various details of internal building, embody the characteristic and the humanistic spirit of modern university library. For example, fully considering reader factors, leave the place that has most natural ventilation and lighting to the reader, to strengthen the humanistic color [8]. University library should create a humanistic environment in the interior design of the interior layout, indoor facilities, indoor decoration, air quality and construction of personalized service space and so on, reflecting the humanistic spirit.

\subsection{Optimize the Collection Structure and Enrich Collection Resources}

Reasonable collection structure can make the library literature information resource utilization rate the biggest, the fund utilization rate the highest, and the service level the best. Reasonably develop a collection ratio of the various types of literature, such as the proportion of used books and periodicals, the collection ratio of the Chinese books and foreign books, the proportion of electronic resources in the library and so on, so as to increase the key discipline resource allocation. Optimizing the collection structure of the library and making full use of the literature information of the library can enrich the resources of the library, and maximize its function.

\subsection{Carry out Diversified Services and Promote the Construction of Harmonious Campus}

With the development of network technology, traditional university library service mode is seriously attacked, and its traditional operating mechanism and working method also are correspondingly changed. In the tide of the construction of harmonious campus, university library service needs to adapt to it. The change of the University library service mode can promote the construction of harmonious campus.

Through computer network collects, processes, and arranges the different geographic locations and different types of information resources, timely transfer literature information to readers and provide information services, so readers can obtain the required information on the Internet in any capacity at any time anywhere. With the combination of network teaching and traditional teaching, the traditional resources are integrated together with network resources. Through the elective courses, training courses and seminars and other forms to provide training service for the readers. Allow users to learn 
how to use the traditional library and the digital library, how to search the literature, different database functions and using method, as well as data sources, online identification, collection and so on.

\section{Conclusion}

University, as an educational institution with the highest academic and cultural level, not only undertakes the task of training high-level talents and leading science and technology innovation, but also takes a mission of leading human society to civilization, rationality, wisdom, and ideas. The library is a symbol of the University, and now the humanistic spirit of the library building is essential in the construction of a harmonious campus. This paper, through the analysis of the necessity of humanistic spirit in University library, contacting the humanistic spirit construction background and development, based on the development of the information technology in modern society and optimization of human environment and collection structure, through the network optimization borrowing and use ways, improves service level, saves readers time, and improves the learning efficiency.

\section{References}

[1] Gong F, Diao Y, Pan T. Evolution of human medical model and development course of medical humanistic spirit [J]. Biomedical Research, 2015, 26(3): 407-414.

[2] Hou J, Geng X, Su Z. Research on Practice Carrier and Method Formed by Medical Humanistic Spirit for Medical Students: Tianjin Medical University as a Case in Point[J]. Chinese Education \& Society, 2014, 47(3): 111-112.

[3] Pei S, Cui F, Sun T. The unity of scientific literacy education and humanistic spirit education in higher education [J]. Creative Education, 2013, 3(07): 121.

[4] Xiao H, Xi C. Study on Institutionalization of Library's Humanistic Spirit_—Based on< Public Library's Service Standards [J]. Sci-Tech Information Development \& Economy, 2013, 1: 030.

[5] Ning W. Highlighting the Humanistic Spirit in the Age of Globalization: Humanities Education in China [J]. European Review, 2015, 23(02): 273-285.

[6] Deshan Y U. Value Pursuit of the Sports Humanistic Spirit_-Academic interview of professor Hu Xiaoming[J]. Journal of Sports and Science, 2013, 2: 004.

[7] Qian F A N. The Focus of the Cultivation of Humanistic Spirit of Colleges-Humanistic Education [J]. The Guide of Science \& Education, 2013, 5: 005.

[8] NI W, LUO L, HUANG H. The 3rd Affiliated Hospital of Kunming Medical University, Yunnan Cancer Hospital, Kunming 650118, China; Humanistic Spirit as Dominant Strength of Neurosurgery Technology Development [J]. Medicine \& Philosophy, 2013, 4. 